\title{
Scammed
}

\section{Malcolm Mendelsohn*}

High Density Hair Transplants, Greece

*Corresponding author: Malcolm Mendelsohn, Greece,

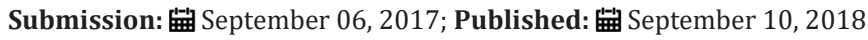

\section{Opinion}

I was scammed recently, yes me, a guy who's spent years warning others about scams in my industry!! I responded to an email from a 'so-called' digital marketing company offering sales leads they claim to have acquired, as a result of a health marketing

campaign. 22,000 responses from people being offered sizeable discounts for hair-loss related services. So, I transferred my money into his account and got a response telling me that the 22,000 emails had risen to 33,000 and they were sending me additional 11,000 emails as a bonus (Figure 1).

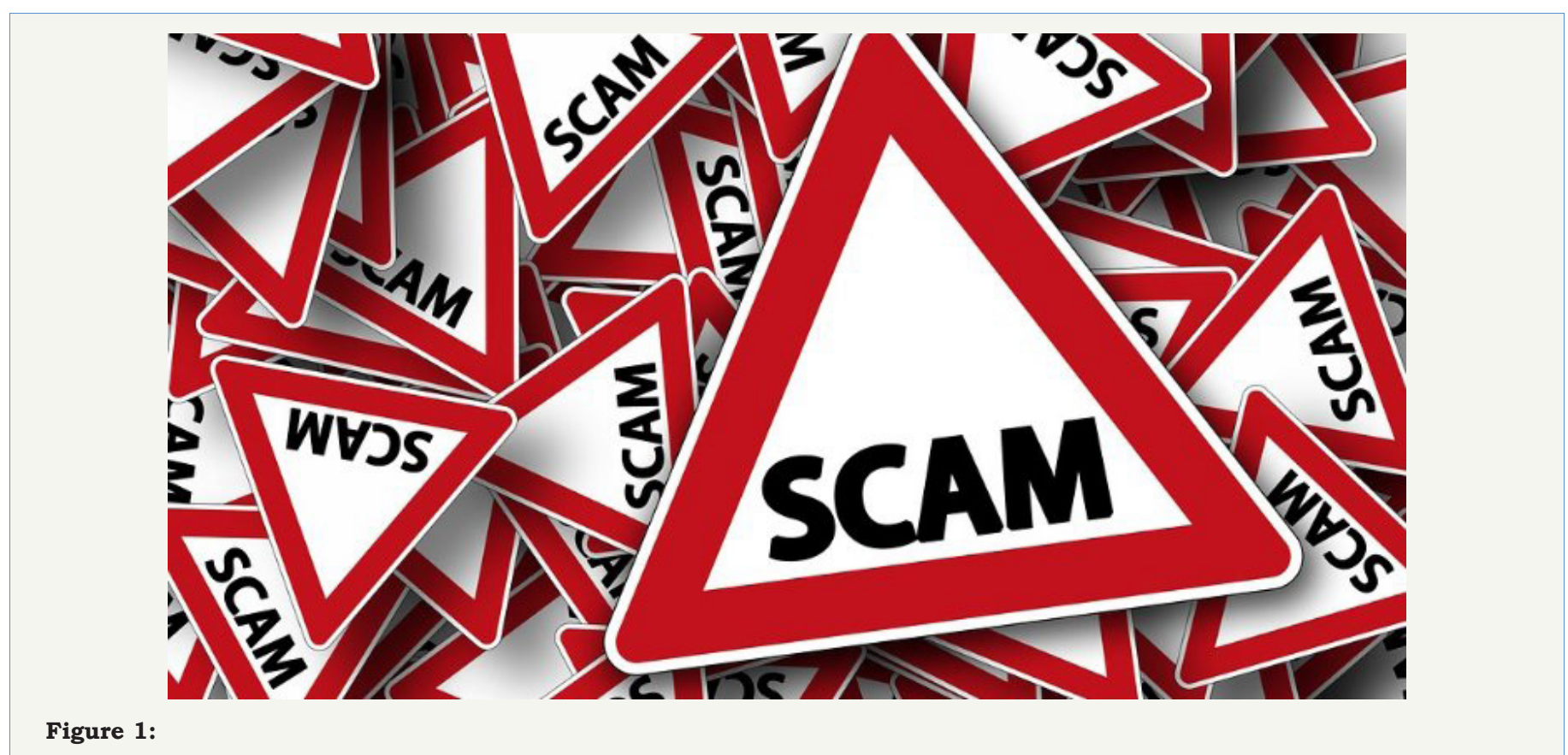

A week later I sent out the $1^{\text {st }} 5000$ emails as a tester. Approximately 4800 went straight to Spam! I contacted the supplier and he gave me several reasons as to why this had happened. He suggested that I make One or Two minor adjustments, one of which was to use a dedicated server and send them out again.

I responded to his email to ask him another question, and lo and behold, my email bounced! I then revisited his website, and yes, you guessed, I got an error message to say that 'this site had been suspended'! That was 3 Months ago and, as the days go by, the anger that I feel at being scammed subsides, little by little, as the memory fades.

Then, I consider myself lucky. Lucky? Yes, very lucky!!
What if I had been scammed, and the damage was permanent. When, every time I looked in the mirror, I was reminded of the abuse?

Like my new friend, who has just written me. He had responded to an advert for hair transplant, and the results were so diabolical that he was left scarred for life?

Can you imagine, having to be faced with such a dilemma $24 / 7$ for the rest of your natural life? It's not worth thinking about!! But, that's what happened to this young man.

He'd responded to an advert from a Turkish hair transplant clinic. A clinic offering him a full-head hair transplant for $£ 2,400$. 
Yes $£ 2,400$ for 4000 hair grafts. The price including his air fare, his hotel costs and his collection and return to the airport.

One can only ask the question, how much of that money was left to pay for his surgery?

The answer is in his results. Look for yourself: (Figure 2)

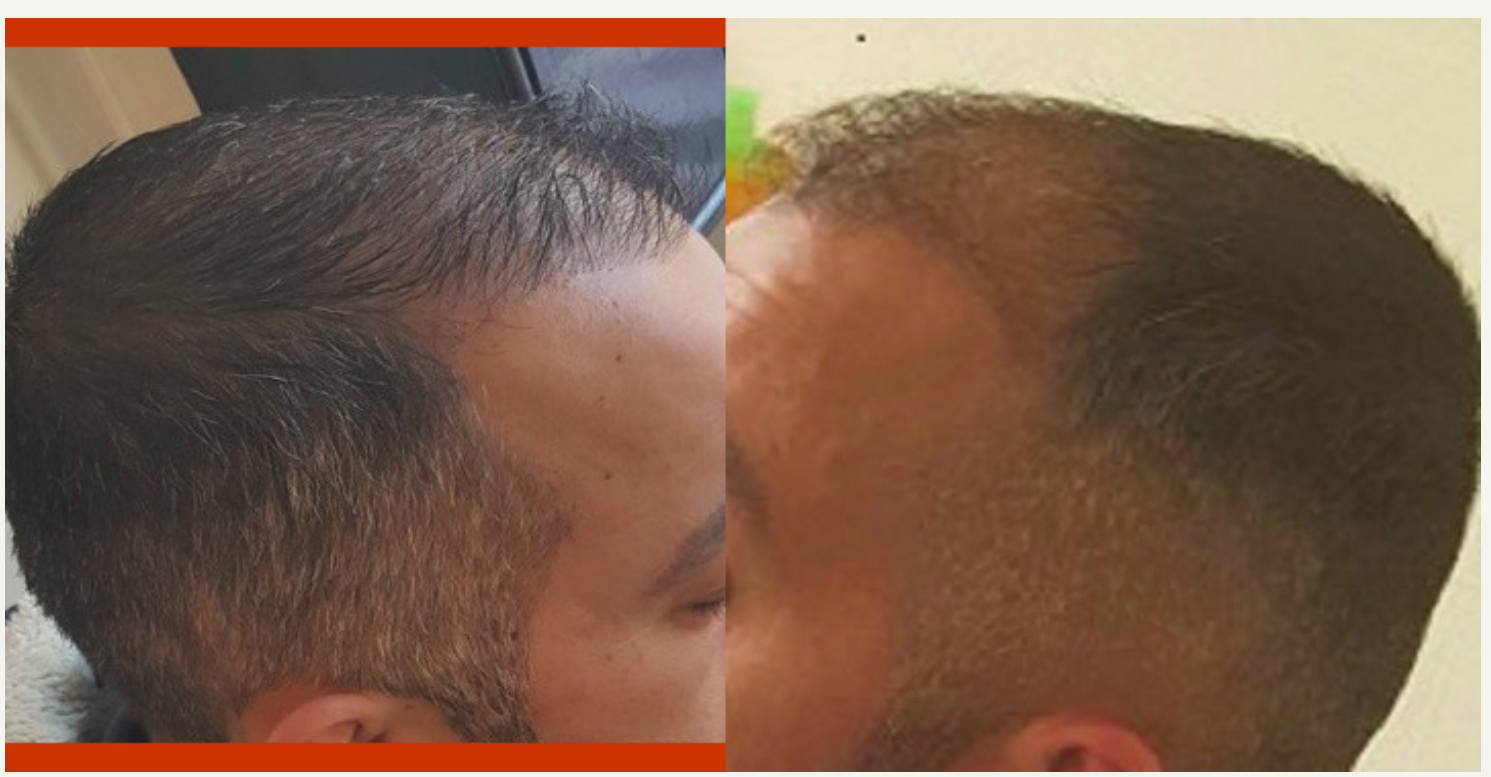

Figure 2:

The Clinic concerned had used 2 hair grafts. Grafts with an average hair content of 2 hairs. Most 'legitimate' clinics use the 'Selection' process. This is when the doctor and his/her team 'select' the hair grafts with the highest hair content. Using magnified 'visors' with which to identify, select and remove the bigger grafts.

Not just single and 2 hair grafts which we use to produce a 'natural' looking hairline but $3 / 4 / 5$ and even 6 hair grafts, to give their patients the most volume/density available, behind the front hairline and top scalp. A process that takes time, and time costs money. A little more than my young friend paid. This clinic had tried to cover a vast area of baldness with low-density 2 hair grafts. The results can be seen. Big gaps between the grafts and areas of baldness behind the patient's ear where the young trainees had over-harvested his donor site. The patient has even been forced to comb part of his thicker, side growth, onto his top scalp to add a little more volume to his 'spaced-out' results.

He told me he'd tried growing the hair longer at the back to disguise the bald patches behind his ears, but the longer he grew his hair, the more noticeable the loss became. $4000 \times 2$ hair grafts, produces approximately 8000 hairs. Whereas, 4000 grafts using the 'selection' process produces up to 10,400 hairs. 2,400 extra hairs that could have meant the difference between a 'see-through' result and a 'natural' looking result? Added to which, Clinics using the 'selection' process could have produced the same number of 8000 hairs by harvesting around 3100 grafts. So, not only did this clinic produce an unacceptable result, they wasted 900 of this patient's grafts. Grafts that he now badly needs to add volume to his 'seethrough' results. Grafts that are no longer available to him. Apparently, the clinic who performed this man's hair transplant didn't use qualified nurses to pluck out his grafts. They, like the vast majority of the Turkish clinics, use young, non-medical trainees to pluck-out the grafts ad hoc. In fact, their young 'victim' told me, the only time he saw the doctor was when his hairline was marked out. The rest of his procedure was performed by assistants.

So Why, when you search for hair transplant clinics on the net, don't you hear of cases like this? The answer is simple. These clinics hire SEO (Search Engine Optimization) experts to 'lose' the negative publicity. They 'push' the complaints to the bottom, out of sight. However, as time goes by and the truth of what's happening in Turkey spreads and institutes like the I.S.H.R.S. (International Society of Hair Restorations Surgeon's) voice their opinions, the truths comes out [1].

The press too has finally highlighted the sheer, criminal enormity of the problem [2]: Even veterans of the industry like me, having written numerous articles on the subject, are beginning to have their views published [3]: Unfortunately, the responses from the top, has come a little too late. Too late to save my unfortunate young friend from a lifetime of using hair-thickening 'fibres' with which to disguise his misfortune. Too late to help the 1000's of guys like him, that have been hidden from public view by a virtual army of S.E.O. experts.

\section{References}

1. http://www.ishrs.org/search/node/Turkey

2. https://www.pressreader.com/uae/the-national-news-busine ss/20161003/281500750747858

3. https://docs.zoho.com/ file/0ku5h0db81c5b59c94600abe0a91534b557e8 
Creative Commons Attribution 4.0 International License

For possible submissions Click Here

Submit Article

$\begin{array}{ll}\text { RMES } & \begin{array}{l}\text { Researchin } \\ \text { Medicl } \\ \text { Engineering } \\ \text { Sciences }\end{array} \\ \text { Benefits of Publishing with us }\end{array}$

